\title{
ESTILOS
}

DOI: https://doi.org/10.11606/issn.1981-1624.v25i3 p471-487.

\section{Artigo \\ O impacto da escola na ideação suicida de adolescentes}

\author{
Adams Friedemann; Joana Narvaez
}

Resumo. Na escola, os adolescentes ampliam seu convício social e vivenciam importantes transformações psíquicas, tornando-a um ambiente propício ao surgimento de condutas psicopatológicas, como a ideação suicida. Por meio de uma pesquisa qualitativa de caráter exploratório, buscamos compreender a percepção de adolescentes quanto à implicação do espaço escolar em sua ideação suicida. Aplicou-se uma entrevista semiestruturada com quatro adolescentes, estudantes de escolas públicas, a qual foi analisada mediante a estratégia clínicointerpretativa. Constatou-se que os participantes não consideram a escola um espaço amenizador de seu sofrimento psíquico. Considera-se importante a presença do psicólogo na escola para possibilitar a criação de novos destinos aos conflitos adolescentes.

Palavras chave: adolescência; suicídio; escola.

\section{El impacto de la escuela en la idea suicida de adolescentes}

Resumen. En la escuela, los adolescentes extienden su vida social y experimentan importantes transformaciones psíquicas, creando un ambiente propenso al desarrollo de conductas psicopatológicas, como la idea suicida. A través de una investigación exploratoria cualitativa, buscamos comprender la percepción de los adolescentes sobre la implicación de la escuela en su idea suicida. Se aplicó una entrevista semiestructurada con cuatro adolescentes, estudiantes de escuelas públicas, que fue analizada a través de la estrategia clínico-interpretativa. Se constató que los participantes no consideran la escuela un espacio mitigante para su sufrimiento psíquico. La presencia de un psicólogo en la escuela es importante para permitir la creación de nuevas vicisitudes para los conflictos adolescentes.

Palabras clave: adolescencia; suicidio; escuela.

\section{The impact of school on the suicidal ideation of adolescents}

Abstract. In school, adolescents extend their social life and experience important psychic transformations, creating an environment prone to the development of psychopathological conducts, such as suicidal ideation. Through a qualitative exploratory research, we seek to comprehend the perception of adolescents regarding the implication of school in their suicidal ideation. We conducted a semi-structured interview with four adolescents,

* Psicólogo. Departamento de Psicologia da Universidade Federal de Ciências da Saúde de Porto Alegre, Porto Alegre, RS, Brasil. E-mail: adamsfmann@gmail.com

** Psicóloga. Professora adjunta da Universidade Federal de Ciências da Saúde de Porto Alegre, Porto Alegre, RS, Brasil. E-mail: jonarvaez@gmail.com 
students of public schools, analyzed through the clinical-interpretative strategy. Our results show that participants do not consider school a mitigating space for their psychic suffering. The presence of a psychologist at school is important to enable the creation of new vicissitudes for adolescent conflicts.

Keywords: adolescence; suicide; school.

\section{L'impact de l'école sur les idées suicidaires des adolescentes}

Résumé. À l'école, les adolescents prolongent leur vie sociale et vivent d'importantes transformations psychiques, créant un environnement propice au développement de conduites psychopathologiques, telles que les idées suicidaires. A travers une recherche exploratoire qualitative, nous cherchons à appréhender la perception des adolescents quant à l'implication de l'école dans leur idéation suicidaire. Nous avons mené un entretien semistructuré avec quatre adolescents, étudiants des écoles publiques, analysés à travers la stratégie d'interprétation clinique. Nos résultats montrent que les participants ne considèrent pas l'école comme un espace atténuant pour leur souffrance psychique. La présence d'un psychologue à l'école est importante pour permettre la création de nouvelles vicissitudes pour les conflits adolescents.

Mots-clés: adolescence; suicide; école.

\section{Adolescência como crise de elaboração}

A literatura psicanalítica caracteriza a adolescência como um período de transformações e conflitos determinantes à vida psíquica do sujeito, dando continuidade a mudanças fisiológicas e psicológicas iniciadas na infância e intensificadas pela puberdade. Há a prevalência de duas temáticas na adolescência: o retorno do complexo de Édipo e sua progressiva resolução, através do desligamento dos objetos iniciais - a partir do que o indivíduo empreende a busca por novos objetos de identificação e de amor, passando por um processo de renúncia aos pais da infância, que pode provocar um sentimento de vazio interior, sofrimento e tristeza (Blos, 1962/1985). Também a perda do corpo e da identidade infantis torna essa fase predominantemente marcada pelo luto (Macedo, Fensterseifer \& Werlang, 2012). O enfrentamento das mudanças corporais e da inserção social começa ainda nos anos da infância, que são acentuadas na fase da puberdade, situação que requer maior esforço para conservar o equilíbrio psíquico que foi abalado pela crise gerada por essas transformações e pelo surgimento de novas demandas sociais. Similarmente, o processo de individuação agora se complexifica, estabelecendo o intuito final de um senso de identidade, progressivamente consolidada, ao custo de experiências conflitivas e de fragmentação egoica (Blos, 1962/1985). Esses fatores configuram o que Freud (1905/2006) denominou de transformações da puberdade.

Concomitantemente à renúncia da infância, o indivíduo deve empreender uma busca por novos objetos - a princípio permeados por características idealizadas - a fim de preencher o vazio deixado pelo desinvestimento nas figuras parentais (Macedo, Azevedo, \& Castan, 2012). Em razão disso, Paz (1978/1983, p. 166) afirma que a adolescência "assinala a segunda grande crise da personalidade", na qual o jovem se diferencia do núcleo familiar e dos cuidados parentais, gradualmente adquirindo autonomia. A elaboração do vínculo de dependência simbiótica aos pais em direção à própria independência constitui a tarefa básica da crise adolescente (Paz, 1978/1983). O caminho até a independência passa pela formação do grupo de amigos, semelhantes ao sujeito - o que denota o objetivo de satisfação das necessidades 
narcísicas -, que ele passa a integrar e reconhecer como seu, quase em detrimento da própria família. No grupo, ele busca pessoas com as quais possa se identificar; trata-se, portanto, do amor a um objeto que possui qualidades que faltam ao ego (Freud, 1914/2006). O grupo serve a uma dupla função: por um lado, seus atos representam a oposição às figuras parentais e a necessidade de formação identitária diferenciada do seio familiar; por outro, possibilita um comportamento defensivo em sua uniformidade, proporcionando segurança e estima pessoal, frente às bruscas mudanças e aos novos desafios impostos por elas (Knobel, 1981/1986).

Aparentemente, $o$ adolescente troca a dependência a seus pais pela dependência a seu grupo. Antes que isso aconteça, no entanto, há uma tendência natural, no começo da adolescência, ao isolamento no próprio mundo interno; isso porque o jovem estava acostumado ao mundo infantil e se vê num rompante de demandas até então desconhecidas, o que lhe causa confusão e medo (Aberastury, 1981/1986). Após esse período, quando o adolescente se afasta do mundo externo e se isola em seu interior, refugia-se contra o que encara como um perigo a sua sobrevivência psíquica, resultado das perdas que deve elaborar.

A adolescência abre caminho a um ser humano diferente daquele que já se conhece na figura dos pais e isso exige do indivíduo uma capacidade criativa que se desenvolve a partir de um ambiente propiciador de mudança. Tal capacidade implica um desprendimento do passado e do presente a fim de possibilitar a projeção do futuro ao qual se almeja. Para que essa problemática seja transposta, é imprescindível proporcionar ao jovem um espaço que lhe possibilite desenvolver sua autonomia pessoal, sua independência da família e sua moratória enquanto um sujeito de desejo, oportunizando-lhe o cultivo de sua singularidade e de seu papel na cultura. Um possível espaço de desenvolvimento psíquico e social é a escola, que desempenha uma função de iniciação social e serve como campo de transição da vida infantil à vida adulta.

\section{A escola como espaço de exercício da subjetividade}

A escola é um espaço de inscrição social cuja responsabilidade não se restringe à ação pedagógica do ensino. Pela educação, a escola tem função coextensiva à dos pais, na medida em que se articula o desejo de educar (entendido como um trabalho civilizatório de inserir o sujeito na cultura) ao desejo de ensinar (Martins, 2001). Embora frequentemente ignorada em detrimento do ensino - aspecto pedagógico -, a função civilizatória - aspecto relacional - da escola se mostra de importância categórica ao adolescente que se desprende da família em busca de sua identidade, pois ele se afasta cada vez mais dos cuidados parentais e das visões de mundo destes, e procura esses elementos faltantes em objetos externos, como professores e amigos. Neste momento, o indivíduo se encontra em uma situação interna de desorientação frente à falta acarretada pela perda da infância, de confusão a respeito de si e de incerteza em relação aos outros e ao mundo. Ele precisa de alguém que o acolha e contenha suas angústias diante das dúvidas que o acometem, e isso vai além da função de ensino (apesar da evidente necessidade deste à existência da instituição escolar).

A escola como um todo e o professor em particular desempenham essa missão de receber o adolescente que quer fazer parte da comunidade, e a isso serve a educação. O desejo de educar se relaciona à disponibilidade subjetiva do educador - que se põe diante da criança ou do adolescente como um modelo identificatório -, bem como de sua responsabilização ao enxergar no educando um sujeito em constituição, e tomando para si responsabilidade parcial por esse processo (Martins, 2001). O crescimento da pessoa não acontece sem desafios, dado que apenas 
recentemente o jovem começou a pensar por si mesmo e a questionar o saber postulado pela família. Agora, o adolescente se vê diante da possibilidade de confrontar o conhecido em busca de um saber próprio, construído por ele e por seus semelhantes. Coutinho (2016) afirma que os adolescentes exigem da sociedade a capacidade de continência de suas experiências subjetivas, desafiadoras da ordem social. Isso se reflete no papel do educador que vai além do ensino, facultando o acesso do jovem à cultura, que assim tenta por seus próprios meios renová-la, e a partir disso surgem os comportamentos denominados de oposição. Daí a necessidade de encarar o movimento questionador e confrontador do adolescente como um trabalho psíquico necessário ao desenvolvimento do sujeito, e não como um ataque ao professor ou aos pais (Coutinho, 2016).

Essa incumbência é difícil e dolorosa, tanto para o educando quanto para o educador, pois exige um constante trabalho de reformulação pessoal, de abertura ao novo, ao diferente e ao desconhecido, o que causa desconforto e desacomodação. Por vezes a escola e os educadores não se sentem preparados a empreender esse trabalho, seja por questões pessoais, de formação pedagógica ou em razão de entraves político-burocráticos, ou ainda uma combinação dos três. Quando esse é o caso, o processo se torna mais propenso a causar a estagnação do educando, barrando qualquer tentativa do adolescente de se diferenciar, de criar e de desejar.

Dussel e Caruso (2003) apontam como não nos surpreendemos com a maneira como a pedagogia replica, molda e forma indivíduos sob a pretensão de dominá-los, ou, em uma palavra, normalizá-los, isto é, adequá-los à norma. Os autores relacionam essa vontade de controlar ao temor provocado pela situação de ensinar (e de educar, acrescentaríamos), que faz o professor se deparar com indivíduos com histórias e desejos diversos e singulares, que os fazem questionar sua capacidade pessoal e profissional. Logo, encontra-se o que Coutinho (2016) aponta como a ambivalência no discurso sobre a adolescência: de um lado, o fascínio; de outro, a necessidade de controle.

Dificilmente o adolescente conseguirá se libertar desse enclausuramento do desejo, pois a partir do momento em que se afasta de casa e se aproxima da escola ele passa a investir nos vínculos estabelecidos ali, tornando-o dependente do espaço que propicia esses relacionamentos. Ao mesmo tempo, ele não aceita ter seu desejo barrado. Surgem então comportamentos transgressores, supostamente desadaptativos. A respeito da denominada adaptação escolar, Mannoni (1979/2005, p. 36. Grifos da autora. Tradução livre) a considera "uma nova forma de 'doença' que não deve ser 'tratada'. Consiste na recusa de se adaptar, sinal de saúde na criança [ou adolescente] que rejeita essa mentira mutiladora na qual a escolaridade a aprisiona". Uma mentira de isonomia e conformidade, que intenta homogeneizar toda singularidade.

A adolescência enquanto fase é vista, externamente, como um momento constantemente desintegrativo, pois rompe com um padrão comportamental estabelecido na infância, influenciado pelos pais, por isso Blos (1962/1985, p. 134) afirma que "os processos integrativos são mais silenciosos do que os desintegrativos". Motivo também pelo qual a adolescência é denominada por Knobel (1981/1986) como uma síndrome normal, ou seja, ela é semelhante a um conjunto de sintomas patológicos, mas que, ao contrário de uma síndrome verdadeira, tem o intuito de integrar uma identidade própria, independente das figuras parentais primordiais. De acordo com Aberastury (1978/1983, p. 13),

Neste período o sujeito flutua entre uma dependência e uma independência extremas, e só a maturidade lhe permitirá, mais tarde, ser independente dentro de um limite de necessária dependência. No começo, mover-se-á entre o impulso ao desprendimento e a defesa que 
impõe a perda do conhecido. É um período de contradições, confuso, ambivalente, doloroso, caracterizado por fricções com o meio familiar e social. Este quadro é frequentemente confundido com crises e estados patológicos.

Uma vez que grande parte dos conflitos e elaborações adolescentes tem por palco o espaço escolar, é compreensível que professores e outros profissionais da educação considerem patológicos os fenômenos que observam nos alunos. De fato, dada a delicadeza dessa fase, é comum que o adolescente vivencie com muito sofrimento e dor essas transformações, possivelmente vindo a adoecer, visto que durante a crise adolescente - que se trata, em última análise, de uma tentativa de elaboração através da dessimbiotização e da reestruturação da visão de si e do mundo - é comum, quando da atrapalhação desse processo, o surgimento de psicopatologias que se expressam de variadas maneiras, como estados de angústia, violência e outros comportamentos nocivos, inclusive condutas autodestrutivas como a ideação suicida e a tentativa de suicídio (Paz, 1978/1983).

\section{O suicídio na cultura: um impasse à escola}

Clinicamente, a ideação suicida pode ser compreendida como um sintoma que tenta restabelecer o equilíbrio simbólico do sujeito quando este vive um trauma sentido como excessivo, ou seja, que ultrapassa sua capacidade psíquica de elaboração (Macedo \& Werlang, 2007b), faltando-lhe objetos pulsionais que deem conta de suportar seu desamparo (Macedo, Werlang \& Dockhorn, 2008). Fenomenicamente, o que se testemunha é uma dor insuportável, por vezes inominável, que leva o indivíduo a enxergar na própria morte a única solução. Sendo assim, o suicida não se mata por não querer viver, ele se mata por não suportar viver seu sofrimento desmedido. Esse fato levou a psicanálise a encarar o suicídio como uma denúncia da fragilidade psíquica do sujeito, que se transforma, através do ato, em um pedido de ajuda (Macedo \& Werlang, 2007b). Não conseguindo colocar sua aflição em palavras, o sujeito fica prisioneiro de sua ação quando enxerga nesta a única representação possível para uma dor incapacitante (Macedo et al., 2008).

Parte constituinte do sofrimento suicida é a angústia, que suscita a dúvida em relação ao que desencadeia o padecimento. Em contrapartida, o ato suicida traz certeza à pessoa: a vida dúbia e indeterminada se torna insuportável e a morte se mostra como uma solução definitiva; o sofrimento não é questionado, é resolvido (Cremasco \& Brunhari, 2009). A angústia humana remete ao desamparo, concebido como falta de garantia do sujeito a respeito do mundo e do futuro. $\mathrm{O}$ desamparo determina a renúncia pulsional como condição para viver em sociedade.

Assim, as psicopatologias surgem quando faltam meios culturalmente legitimados de lidar com os conflitos derivados da imposição de um tipo psicológico ideal, constituindo-se como um entrave ao processo civilizatório (Macêdo, 2012). Dada essa constatação, e considerando como uma das funções da escola a criação de possibilidades para a inserção do sujeito na cultura, agindo como um facilitador dessa passagem da infância à adolescência e desta à idade adulta, é imprescindível reconhecer a relevância da instituição escolar na vida do jovem, que nesse momento de vida passa por importantes transformações de seus conflitos internos. Essas transformações, por seu caráter traumático, expressam na vida da pessoa a ausência de atribuição de sentido (à vida e ao mundo), ainda por se constituir. Esse fato mostra que o ato ou ato-dor, de acordo com Macedo e Werlang (2007a; 2007b) - denuncia a existência do vazio, 
motivo pelo qual a experiência escolar pode falhar em evitar o suicídio em todas as suas formas, uma vez que a escola pode deixar de fazer sentido ao adolescente que cresce e questiona, e não se conforma com o que está aí, com o incontestável, com o indiferenciado. A escola pode então falhar em proporcionar ao jovem a liberdade necessária a sua maturação intelectual e emocional. Pois, conforme recomenda Freud (1910/2006, p. 245), "uma escola deve conseguir mais do que não impelir seus alunos ao suicídio. Ela deve lhes dar o desejo de viver".

O crescimento do adolescente é permeado por conflitos e elaborações psíquicas significativos ao seu amadurecimento, eventualmente vindo a desencadear psicopatologias que podem se expressar pela ideação suicida ou evoluindo para questões mais graves como tentativa de suicídio ou sua consumação. Por atravessar grande parte desse processo na escola, torna-se crucial investigar o enlace entre esses elementos. Respaldado por essas considerações, o objetivo deste estudo é compreender a implicação do espaço escolar na ideação suicida de adolescentes, segundo as reflexões dos próprios estudantes. Ademais, propõe-se a escuta do sujeito como uma forma de atenuar o sofrimento causado pelos conflitos próprios à adolescência, atravessados pelas vivências do ambiente escolar, tonando-se importante a presença do psicólogo nesse âmbito institucional, que se proponha à tarefa de fazer circular a palavra.

\section{Método}

Trata-se de uma pesquisa qualitativa, de caráter exploratório. Participaram deste estudo quatro adolescentes com idades entre 14 e 16 anos, estudantes dos ensinos fundamental e médio de escolas estaduais de Porto Alegre, RS. A amostra foi alcançada por conveniência, por meio de indicações do serviço psicopedagógico e corpo docente das escolas. Esta pesquisa foi aprovada por Comitê de Ética em Pesquisa.

Após comunicação com as escolas, a fim de mapear possíveis participantes para o estudo, os pesquisadores entraram em contato com os adolescentes para explicar o objetivo, o método e os potenciais riscos e benefícios da pesquisa. Posteriormente, foram solicitadas leitura e assinatura do Termo de Consentimento Livre e Esclarecido e do Termo de Assentimento por parte dos jovens e seus responsáveis legais.

A coleta de dados foi realizada por meio de uma entrevista semiestruturada (Anexo), elaborada pelos pesquisadores, composta de perguntas a respeito do adolescente e de sua vida na escola, com o propósito de investigar o impacto da escola em sua ideação suicida. A entrevista foi aplicada individualmente e gravada em áudio, subsequentemente transcrita na íntegra. Todas as entrevistas foram realizadas nas respectivas escolas de cada aluno.

Considerando a complexidade dos fenômenos abordados e os objetivos deste trabalho, a análise dos dados coletados foi realizada mediante a estratégia clínico-interpretativa (Dockhorn \& Macedo, 2015), que admite a ampliação do método psicanalítico para além da clínica, com o intuito de subsidiar as diferentes formas de pesquisa social. As autoras assinalam que, pautada na concepção do sujeito singular detentor de um saber inconsciente, a pesquisa que se utiliza do método psicanalítico toma como seu fundamento técnico os mesmos instrumentos estimados pela clínica, a saber, a escuta, a abstinência, a transferência e a interpretação.

A estratégia clínico-interpretativa preconiza dois momentos (Dockhorn \& Macedo, 2015): $1^{\circ}$ ) de escuta, ou seja, de construção da narrativa acerca do fenômeno estudado, por parte do público-alvo; e $2^{\circ}$ ) de análise, que possui a finalidade de refletir a respeito dos elementos 
presentes no material. Para o segundo momento, de análise de dados propriamente dita, fez-se uso do referencial teórico da psicanálise para a interpretação dos sentidos emergentes do discurso dos adolescentes entrevistados. Apesar de almejar a investigação a respeito de qual a ordem da relação da escola com suicídio na adolescência, a pesquisa psicanalítica não possui a intenção de explicar, linear e casuisticamente, essa relação. À estratégia clínico-interpretativa subjaz o rigor dos elementos básicos do fazer psicanalítico, pressupondo a abertura ao inesperado no encontro com o sujeito.

\section{Resultados e discussão}

Dentre os quatro participantes, havia três meninas e um menino. Ao longo das perguntas, foi possível notar que surgiram temáticas comuns aos estudantes, embora também se tenha constatado que cada um deles vivencia suas experiências de forma singular, demonstrando diferentes percepções e sentimentos quanto a fatos semelhantes. Durante a entrevista, foram abordadas questões referentes à personalidade dos participantes, suas vidas familiar e estudantil, bem como os afetos mobilizados por seu cotidiano escolar.

Os dados coletados serão aqui organizados de modo que se construa uma narrativa sobre o fenômeno estudado. Em um primeiro momento, será enunciado o sujeito por trás do aluno, mostrando como os participantes enxergam a si mesmos e sua personalidade, apresentando ainda sua vida familiar e suas relações interpessoais; por fim, será descrito como esses adolescentes vivenciam sua ideação suicida. A importância dessa exposição se dá ao fato do papel desempenhado pela família e pelo convívio com o outro na constituição psíquica do indivíduo, que determina o modo como se relacionará com o mundo, podendo vir a desencadear o sofrimento psíquico e a ideação suicida. Em um segundo momento, será explorado o tópico da escola e o desejo de viver, isto é, como os adolescentes experenciam seu cotidiano escolar e o impacto que a escola exerce sobre o mal-estar dos sujeitos, servindo como fator de proteção ou de agravamento em relação à ideação suicida. Finalmente, investigaremos o papel que a psicologia pode desempenhar no espaço escolar a fim de tornar a experiência estudantil menos dolorosa e mais propícia à construção de novas possibilidades ao adolescente em desenvolvimento.

\section{O sujeito por trás do aluno}

Os adolescentes entrevistados apresentaram certa dificuldade em dialogar sobre si, descrever sua personalidade e mencionar o que os deixa felizes ou tristes. Claramente, uma resposta nesse sentido se constituiria necessariamente como temporária, visto que a transição pela adolescência implica a construção de uma identidade que apenas mais tarde se consolidará. Apesar da relativa dificuldade em responder aos questionamentos, observou-se que os jovens têm necessidade de falar.

Giovana ${ }^{1}, 14$ anos, descreve-se como uma pessoa "que tenta ajudar os outros, mas que não quer ser ajudada"; sua fala insinua que, no passado, ao procurar a ajuda das pessoas, acabou por se decepcionar. Martha, 16 anos, fala de si como "bipolar, com altos e baixos", revela que

\footnotetext{
${ }^{1}$ Os nomes dos participantes foram substituídos por nomes fictícios, com o intuito de preservar o sigilo de sua identidade.
} 
é "oito ou oitenta, e às vezes eu tô feliz, mas por dentro eu tô morta". Demonstra funcionar entre extremos e, apesar de falar bastante, protege-se contra seus sentimentos. Karen, 16 anos, diz ser "muito curiosa" e que tenta ser "boa com as pessoas", ainda que seja bastante fechada; demonstra bastante sensibilidade e por vezes seu discurso se torna confuso e desorganizado, o que talvez denote particular dificuldade em atravessar os conflitos que perpassam a família e a escola. Evandro, 16 anos, caracteriza a si mesmo como um "cara extrovertido", que não é "recluso", mas que não fala dos sentimentos, porque "geralmente quando eu falo, não me ouvem", além do que "eu não sinto que alguém tenha que me ouvir falando". Questionador, Evandro parece usar disso para se distanciar de seu afeto, por vezes rebatendo as perguntas do entrevistador.

Conforme demonstram os entrevistados, as intensas formas de sentir da adolescência, frequentemente manifestas através de polaridades extremadas e oscilantes - como espírito gregário e retraimento para a solidão, otimismo sem limites e desesperança total (Blos, 1962/1985) -, parecem se coadunar plenamente à vivência dessa fase como uma crise, momento de grande tensão no qual o conflito entre o sujeito e a cultura se denuncia explicitamente. $\mathrm{Na}$ adolescência, o indivíduo passa a buscar satisfação em objetos externos, isto é, no outro, e não mais no eu (Blos, 1962/1985), razão por que a dificuldade de se relacionar com semelhantes pode levar o indivíduo a adoecer, tornando-se um grande problema para o desenvolvimento emocional, que se liga intimamente ao desenvolvimento social. Nesse sentido, os quatro participantes expõem dificuldades pessoais em se relacionar e estabelecer vínculos com as pessoas. Giovana declara que não consegue pedir, falar ou se abrir com os adultos. Martha admite não ter muitos amigos e que algumas pessoas já se afastaram dela por ela ter se afastado primeiro. Até recentemente, era difícil para Karen se conectar com os colegas, o que mudou quando foi transferida para sua escola atual, onde sente que consegue se vincular mais profundamente aos amigos, "de vez em quando a gente fica até depois da aula. A gente fica conversando aqui, porque é um lugar bem calmo"; ainda assim, desagrada-lhe quando há aglomeração de pessoas, situação que a deixa inquieta. Evandro menciona que tem poucos amigos e não parece ter estabelecido vínculos reais com seus colegas. Afirma não "sentir nada por ninguém".

Freud (1930/2006) assevera que o relacionamento com as outras pessoas é uma das maiores fontes de sofrimento do ser humano, contra o qual ele busca se defender recorrendo ao isolamento. O outro é fonte de sofrimento porque, em sociedade, somos obrigados a abrir mão de grande parte de nossas vontades e nossos desejos, causando então uma permanente sensação de mal-estar e descontentamento. Se essa "frustração cultural" (Freud, 1930/2006, p. 104) não é compensada de alguma forma, corre-se o risco de se desencadear um desequilíbrio causador de graves quadros sintomáticos. Diante dessa dificuldade de se relacionar que obstaculiza o vínculo, o adolescente, comumente, busca o isolamento como uma solução para a carência de objetos de amor e de identificação.

Isso é notável pelo fato de que os quatro entrevistados mostraram ter um importante laço com a solidão. Giovana diz que "tem dias que eu só quero ficar no meu canto, de boa, sozinha". Martha fala que passa muito tempo sozinha e se contradiz em seu sentimento, em um aparente ato falho sobre um bem/mal necessário: "Eu me sinto sozinha... Eu odeio ficar sozinha, porque eu sempre acho que alguma coisa ruim vai acontecer quando eu tô sozinha, mas... é um bem necessário, às vezes. Mas ultimamente eu tô gostando mais de ficar sozinha do que de ficar com alguém". Karen se sente sozinha a maior parte do tempo, o que muito a incomoda, atribuindo a causa disso a sua personalidade "fechada". Evandro comenta que "eu não vejo 
mais necessidade de me relacionar socialmente com as pessoas. Sinto que eu tentei e cagaram na minha cabeça, então eu parei de tentar", o que justifica sua solidão, pois "eu sempre fiquei sozinho, assim, na vida".

Frente a esse sentimento avassalador de solidão, o adolescente pode buscar refúgio em seu universo interno, como, por exemplo, em romances e livros, que faz Martha sonhar alto e criar seu próprio canto, "o mundo perfeito, que tudo dá certo ... colorido, de unicórnios, de algodão doce". Ou, ainda, um mundo contido nos limites de um quarto, onde Karen admite passar bastante tempo no computador, uma vez que é "no computador que eu encontro tipo um refúgio pras coisas no geral"'.

Outra possibilidade que constitui uma tentativa de se refugiar dos conflitos ensejados pela adolescência é o suicídio, que se revela de diversas maneiras, podendo surgir como um pensamento difuso, talvez evoluindo para a ideação suicida e a tentativa de suicídio, tendo como seu desfecho mais grave o suicídio consumado. Os quatro participantes manifestaram ideação suicida e dois deles (Giovana e Evandro) informam que já se automutilaram - aparentemente, sem a intenção de se matar. A automutilação reflete o que se denomina de passagem ao ato, na qual, conforme Birman (2014, p. 98), "a ação é rude e brutal, não revelando mais qualquer rastro de simbolização". Contudo, mais do que vontade de morrer, o que as ocorrências de automutilação e de ideação suicida enunciam é um pedido de ajuda, pois, segundo Calligaris (2011, p. 39), “quando um pedido não encontra uma palavra que no mínimo reconheça sua relevância, normalmente seu autor levanta a voz", o que acarreta um grito de ajuda que pode se materializar pelo ato ao invés de pela palavra. $\mathrm{O}$ ato automutilador ou suicida se circunscreve em uma dinâmica na qual o irrepresentável conduz ao predomínio do traumático (Macedo \& Werlang, 2007a), que acontece quando o afeto não encontra amparo representacional e irrompe na pele, que delimita a realidade e a relação entre o sujeito e o mundo externo.

Giovana declara que muitas vezes já pensou em se suicidar, explicando que

Eu penso que não tem outra saída. Tipo, meus problemas vão continuar e eu não tô conseguindo lidar com eles. . . penso em me matar porque eu não tenho outra solução e assim minha vida seria melhor. Que acabaria com todos os meus problemas, que eu não estaria sobrecarregada e que eu não ia mais me preocupar com mais nada.

Martha conta que já cogitou se matar, mas reprimiu essa consideração ao pensar na família, principalmente no sofrimento que causaria à mãe. Imputa sua ideação suicida à solidão, apontando que "às vezes ela é boa pra mim, às vezes ela é horrível . . Eu odeio ficar sozinha, mas ao mesmo tempo eu adoro ficar sozinha. E eu tenho muitos medos, eu sou a rainha do medo. E meu medo é ficar sozinha".

Karen é a única participante que afirma nunca ter pensado em tirar a própria vida, no entanto menciona que pensa em sumir, "querendo que alguma coisa aconteça pra eu não voltar mais. . . basicamente morrer, mas não é que eu tenha tentado me machucar ou cometer suicídio. Não sei explicar, eu só... confesso que se isso acontecesse, iria... sei lá... iria ficar mais em paz". Sua ideação suicida é velada, não a expressa em palavras explícitas nem a confere um lugar em sua vida consciente. Evandro, por sua vez, é o extremo oposto disso, expondo que pensa frequentemente em se suicidar. A respeito de suas "crises depressivas", conta que "parecia que pra eu me matar tava a 15 minutos de distância . . provavelmente vou acabar entrando nisso de novo. Sei lá, amanhã ou depois, semana que vem... nunca sei". No tocante a esse pensamento, comenta que "não tem muito o que fazer". Evandro discorre sobre o tema de forma cindida de afeto, como se fosse um assunto sem importância, o que sugere um mecanismo de defesa ligado a uma autoestima defasada, apesar de sua fala ostentar segurança e autoconfiança. 
Quando o sujeito não é capaz de elaborar seus conflitos, quando não consegue significar a sua dor nem simbolizar o sofrimento e contê-lo em palavras, ele vislumbra no ato uma alternativa cabal, como é o caso da automutilação, identificada entre dois dos adolescentes entrevistados, questão já debatida e que aqui se expressa novamente. Por isso, os jovens entrevistados cogitam ou cogitaram o suicídio, pois "o que o sujeito não encontra na realidade psíquica tenta capturar no registro do real" (Birman, 2014, p. 44). A vivência da angústia e da falta de sentido faz emergir a condição original do ser humano - "sujeito desamparado por vocação" (Birman, 2017, p. 40) -, cujo reflexo cultural se inscreve em sua subjetividade na forma de mal-estar. Daí a importância, para o jovem, de encontrar espaços que favoreçam sua capacidade de colocar em palavras sua angústia e sua solidão, uma vez que o sujeito desamparado vive, diante de exigências pulsionais e mundanas, uma experiência de excesso que o obriga a realizar um trabalho de significação dessas forças irruptivas a fim de conter sua intensidade desmedida (Birman, 2017).

\section{A escola e o desejo de viver}

O mal-estar "deve ser tomado como algo constituinte das relações humanas, que se presentifica no cotidiano escolar enquanto prática e discurso" (Carneiro, Souza, Coutinho \& Silva, 2016, p. 549). Conforme observado nas entrevistas, ambos os aspectos do mal-estar prático e discursivo - se realizam na rotina escolar de modo mais ou menos latente, tendo sua presença enunciada pelo sofrimento psíquico e pela ideação suicida. Sobre a relação que a escola possui com esses fenômenos, os adolescentes expressaram opiniões variadas. Martha refere que, quando está "para baixo", é ruim ir para a escola, pois se incomoda com os questionamentos das pessoas. Giovana também se aborrece quando os outros fazem muitas perguntas - "às vezes nem a gente sabe por quê" - e julga que, nesses momentos, piora ao ir para a escola, pois "eu vejo as pessoas rindo e penso 'poxa, eu podia tá rindo também, mas eu não tô. Eu tô aqui pensando em merda, tô pensando em como piorar a minha vida". Nesse sentido, Evandro exprime um ponto de vista semelhante, ao dizer que ir para a escola nessas condições é "uma merda. Ver todo mundo assim, feliz lá, e eu ruim..."; contudo, ele declara que, por vezes, melhora ao ir para a escola, pois lá encontra seus amigos que o fazem rir e o distraem de sua "negatividade". Karen acredita que fica melhor ao ir para a escola "porque a escola me distrai bastante das coisas".

Quanto aos sentimentos despertados pela vida escolar, todos comunicaram que a escola serve como uma distração contra as emoções que os abalam, seja no encontro com amigos ou com professores. Apesar disso, Giovana e Evandro enxergam a escola como um dever; segundo ela, é necessário estudar para "ser alguém na vida", todavia, relata sua recente dificuldade em se manter investida nos estudos: "eu era ótima em todas as matérias. Eu tinha foco, eu tinha atenção, eu tinha vontade. Esse ano meu caderno tá quase todo em branco por eu não ter vontade de copiar. Eu olho assim pro quadro e penso: "pra quê?"'. Tavares (2010, p. 36) nota que "o tempo da contemporaneidade não favorece a subjetivação das experiências, produzindo, assim, sujeitos vazios de significados e referenciais de identificação". Por não conseguir capturar o significado da experiência da sala de aula e com o propósito de não precisar suportar esse vazio, o aluno pode se retirar da cena, como é o caso de Martha, que admite não conseguir ficar em sala quando não apreende um sentido para a situação de aprendizagem; o mesmo acontece com Karen, que ocasionalmente fica ansiosa durante as aulas e precisa se distanciar. 
Em alguma medida, as três meninas demonstram preocupação com as notas escolares, temendo repetir de ano. Karen fala que "eu tenho um pouco de medo de não conseguir recuperar essa nota" e Giovana diz que se sente sobrecarregada e que se incomoda com a rigidez e a incompreensão de alguns professores, além de afirmar que gosta do horário do intervalo por não precisar se preocupar com as matérias, poder ficar com os amigos e esquecer seus problemas. Evandro, ao contrário, mostra-se imperturbado com essa questão, aponta que tem "poucas faltas" e que os professores geralmente gostam dele, conta também que há aulas em que se destaca, nas quais "sempre sabia o que dizer".

Conscientemente, os estudantes não consideram que exista uma forte relação entre a escola, seu sofrimento psíquico e sua ideação suicida. Giovana não soube refletir a respeito desse assunto. Martha alude sua ideação suicida às responsabilidades estudantis, que atingem sua autoestima - "Tá tudo desmoronando de novo" -; Karen não pensa que a escola influencie em sua vontade de sumir; e Evandro não atribui à escola qualquer ligação com sua ideação suicida, minimizando a relevância que aquela ocupa em seu pensamento: "nunca aconteceu nada demais aqui pra eu querer me matar".

Apesar das opiniões manifestas, é possível notar em diversos momentos da fala dos entrevistados, como já foi indicado, que a escola e as experiências que ela ocasiona ocupam lugar importante em suas vidas, inclusive no que diz respeito a seus psiquismos, seja como um fator de proteção contra o sofrimento emocional ou como um elemento agravante deste. Sinal disso é o fato de que três dos adolescentes pensam que outros colegas se sentem da mesma forma que eles. Nas palavras de Evandro: "Tem uma galera aí que eu converso que tem umas paradas assim que nem eu", mostrando que, mesmo que tacitamente, o sentimento de desamparo acomete os adolescentes, outorgando à constituição subjetiva - que se dá a partir da inscrição pulsional no encontro com a alteridade - um caráter traumático e irredutível (Barbosa, 2008). A partir de sua inserção na cultura, o indivíduo se constitui sujeito psíquico, dependendo sempre do outro para existir enquanto ser social, o que remete à sua condição de desamparo perante o mundo. $\mathrm{O}$ caráter traumático subjacente à condição do desamparo está no excesso que advém do encontro com o outro - desde o encontro com os objetos originários até a reprodução deste encontro com objetos subsequentes -, que possui expectativas e exigências a respeito do eu que este nem sempre está apto a atender, fazendo então advir o mal-estar que se manifesta nos diversos tipos de adoecimento, sinalizado, dentre outras formas, pela automutilação e pela ideação suicida.

Desse modo, através do ato (ou sua contemplação), o sujeito denuncia sua dor psíquica ao mesmo tempo em que tenta se proteger do traumático (Macedo \& Werlang, 2007b), dor que muitas vezes não é acolhida pela instituição. Segundo os participantes, a implicação da escola na tarefa de amenizar ou conter o sofrimento psíquico dos estudantes é irresoluta, inclusive no que concerne à ideação suicida. Na percepção de Giovana e Martha, há poucos professores que tentam acolher os conflitos dos alunos. Martha, entretanto, indica que há um a professora em particular que se disponibiliza a ajudar os adolescentes, pois "ela busca nos entender, mesmo não entendendo" e a percebe como "a psicóloga de todos os alunos". Karen não sente que a escola proporcione apoio propriamente dito, mas um momento de distração, conforme mencionado anteriormente. Evandro admite que exista o serviço psicopedagógico voltado a auxiliar os estudantes que necessitem, mas confessa que nunca buscou ajuda por não lhe parecer que seja suficiente, nem eficiente. Giovana e Martha têm opinião similar, a primeira afirma que, quando surgem problemas na escola, 
eu tenho que ter paciência. E eu tenho que engolir de uma maneira ou de outra, porque eu não tenho outra escolha. Eu não tenho como dizer que eu não vou... Porque senão já dão um zero, qualquer coisa mandam pro SOE, pra Diretoria. Aí não dá. Eu tenho que lidar com os problemas, tenho que engolir e tenho que aceitar.

Os adolescentes não parecem enxergar os dispositivos escolares como uma forma de amparo diante das adversidades da vida estudantil. Ao contrário, consideram-nos aparatos vigilantes e punitivos, que não servem ao trabalho de continência necessário ao sujeito que vivencia os conflitos da adolescência.

Indo ao encontro da impressão dos estudantes, Carneiro et al. (2016) apontam que o malestar se manifesta, no que se refere ao outro, em dois polos na adolescência escolar: no primeiro, como falta ligada à impossibilidade de garantia, ou seja, o outro que não dá certeza ao sujeito; no segundo, o outro que não valida o sujeito naquilo que ele é e produz. De um lado, o adolescente esbarra na impotência; de outro, no desvalor. Ao mesmo tempo em que o jovem não enxerga no outro (personificado na figura do educador) uma salvaguarda contra sua dor, não sente que lhe seja conferido um espaço que permita significá-la. Não obstante, os autores colocam que o mal-estar pode ser motor de produção da diferença (contrário à tendência de patologização e busca pelo expurgo do sintoma e da doença) na medida em que ele abre a possibilidade de confronto da incógnita que tensiona e que se encontra presente em toda e qualquer relação social.

A partir dessa constatação, torna-se difícil vislumbrar uma alternativa ao desamparo do adolescente na escola. Contudo, uma possibilidade indicada pelos alunos foi uma abertura, por parte da escola, para a escuta dos sujeitos que transitam no espaço escolar: "tendo mais conversa", como sugere Giovana. O sujeito fica prisioneiro de sua ação quando enxerga nesta a única representação possível para uma dor incapacitante, de modo que ele fala de uma falta de palavras (Macedo et al., 2008). Cohen et al. (2001) pontuam que a palavra, por não ser mais o grande veículo do laço social, cada vez mais perde sua potência.

\section{A escuta do sujeito e o papel do psicólogo}

Nesse sentido, três dos entrevistados consideram relevante a presença da psicologia na escola: Karen faz referência ao momento, no passado, em que havia um grupo de psicólogas em sua escola fazendo uma intervenção com os alunos, dispondo-se a conversar com eles; Evandro e Martha pensam que o trabalho do psicólogo na escola seria benéfico aos alunos que adoecem psiquicamente. O que os quatro jovens sugeriram, explícita ou implicitamente, como uma forma de fazer da escola um espaço que viabilize o desejo de viver, é uma presença que escute o sujeito por trás do aluno e que acolha os conflitos e a dúvida que marcam essa fase da vida.

Assim, quiçá seja possível conter o sofrimento psíquico que acomete o tecido social daqueles que se dispõem a aprender dia após dia o que significa fazer parte da cultura, pois "A educação não se reduz apenas a receitas formatadas, a alguns saberes planejados ou a racionalizações de comportamento, mas a um sistema de gestos, valores, proibições, pulsões e subversões que devem ser descritos noutro feixe de relações" (Pereira, 2013, p. 489). Educar é também cuidar e relacionar, a partir da posição na qual o professor é colocado pelo aluno, e que é legitimado (ou não) pela escola, pelo Estado e pela sociedade. Em resposta ao questionamento de como a 
escola pode fazer advir o desejo de viver em seus alunos, Pereira (2013, p. 549) é decisivo: "fazer circular a palavra".

Gurski (2014, p. 176) afirma que "em meio às condições adversas e nada ideais, é possível construir espaços potentes de circulação da palavra e de produção criativa". Seria justamente esse o papel do psicólogo na escola, guiado pelos princípios teóricos e técnicos da psicanálise, por exemplo. De acordo com Macedo e Werlang (2007a, p. 194),

Defender o acesso a um espaço de escuta é acreditar no valor da vida e na capacidade de enfrentamento psíquico dos conflitos. Caberá, sim, a esse profissional mobilizar todos seus recursos técnicos e humanos para, muitas vezes, inaugurar um olhar de esperança àquele que sofre. Acredita-se que nomear a tentativa de suicídio com um ato-dor, decorrente da vivência do traumático, é trazer para o centro da cena analítica a possibilidade de historizá-lo.

A contribuição da psicanálise é o seu trabalho de escuta das dores que atravessam a vida humana, que cerceiam o desejo e obstruem a subjetivação. A psicanálise implicada no espaço escolar não possui o intuito de se intrometer na função pedagógica de ensino e transmissão de saberes. O que ela pode fazer é tornar menos penoso o processo de inserção na cultura, tarefa que diz respeito ao aspecto educacional, o qual a escola exercita espontaneamente. A psicanálise tem, então, o dever de trazer a palavra à sala de aula, pois "o objetivo de um profissional orientado pela psicanálise na escola é o de abrir um espaço para a circulação de discursos, naquelas instituições em que a ausência dessa circulação estiver comprometendo a realização dos objetivos institucionais" (Kupfer, 2007, p. 137).

Perante o discurso totalizante de toda e qualquer instituição, é assim que a psicanálise se posiciona no espaço escolar, ao valorizar a palavra do sujeito e dar voz a sua singularidade, em direção oposta à da homogeneização. A mobilização do desejo e a desconstrução das resistências possibilitadas pelo fazer psicanalítico possibilitam a circulação da palavra e a emergência do sujeito, antes soterrado pelo discurso endurecido do funcionamento escolar. Em última análise, portanto, o que falta à escola é uma presença que volte a conceder à palavra seu legítimo espaço social.

\section{Considerações finais}

Percebeu-se a influência que uma dimensão da vida do adolescente desempenha sobre a outra, e, de forma mais indeterminada, o impacto que a escola exerce sobre o seu adoecimento psíquico e a sua ideação suicida. Ficou claro que, por trás do estudante que se atenta ou se distrai em sala de aula, que se empenha em tirar notas altas ou que não consegue passar de ano, há um humano em constituição, um ser psíquico que se depara com um mundo social que o assusta e o intriga, e que se sente convocado a agir na cultura de forma que faça parte dela. Muito manifestamente, a experiência da entrevista mostrou que, por trás do aluno, há um sujeito que urge ser escutado.

Em suma, a entrevista revelou que os adolescentes, apesar de não perceberem a escola como um ambiente motivador de sua ideação suicida, também não a percebem como um espaço que alivie seu sofrimento psíquico. Em meio às demandas escolares e à eventual pressão causada por estas, sentimentos de tristeza e solidão se fazem presentes entre os estudantes, que não encontram nos educadores figuras com as quais podem compartilhar seus conflitos internos, seja devido à indisponibilidade dos educadores, seja em razão da dificuldade dos jovens em manifestá-los por meio de palavras. Por se tratar de um espaço de passagem e mediação entre 
a família e a sociedade, a escola desempenha importante papel na vida adolescente, podendo servir como um fator de proteção à sua saúde psíquica. Quando o risco se sobrepõe à proteção, o que se percebe é uma repetição que se manifesta na ideação suicida, ou seja, na contemplação do ato, ou ainda na evolução dessa para uma tentativa de suicídio, concretização do ato que advém da impossibilidade psíquica de elaboração. $\mathrm{O}$ fenômeno da atuação, demarcado ao longo do trabalho, perpassa os diferentes âmbitos da vida dos sujeitos, chegando à escola da forma que se identificou por meio da entrevista com os adolescentes.

Diante desse cenário, é necessário pensar o desenvolvimento de intervenções em médio e longo prazos, que façam da escola um espaço que possibilite transformações dos conflitos que permeiam a adolescência. Cada vez mais adquire extrema importância a capacitação dos educadores para trabalhar com um sujeito que demanda da escola mais do que o ensino, que reivindica cuidado e possibilidade de transformação social. Além disso, torna-se urgente a presença do psicólogo na escola, enquanto profissional que se dispõe a escutar o sujeito de desejo, conferindo assim um novo destino ao sofrimento psíquico do jovem que se propõe a aprender e a fazer parte da cultura.

\section{Referências}

Aberastury, A. (1986). O adolescente e o mundo atual. In A. Aberastury \& M. Knobel. Adolescência normal: um enfoque psicanalítico (S. M. G. Ballve, trad., 5a ed., pp. 88-90). Porto Alegre, RS: Artes Médicas. (Trabalho original publicado em 1981)

Aberastury, A. (1983). Adolescência. In A. Aberastury (org.). Adolescência (R. Cabral, trad., 2a ed., pp. 15-32). Porto Alegre, RS: Artes Médicas. (Trabalho original publicado em 1978)

Barbosa, A. C. A. (2008). A angústia como incidência clínica do irrepresentável da pulsão: desamparo, trauma e repetição. Reverso, 30(56), 41-60. Recuperado de http://pepsic.bvsalud.org/pdf/reverso/v30n56/v30n56a05.pdf

Birman, J. (2014). O sujeito na contemporaneidade. Rio de Janeiro, RJ: Civilização Brasileira.

Birman, J. (2017). Mal-estar na atualidade: a psicanálise e as novas formas de subjetivação. Rio de Janeiro: Civilização Brasileira.

Blos, P. (1985). Adolescência: uma interpretação psicanalítica (V. Dutra, trad.). Rio de Janeiro: Martins Fontes. (Trabalho original publicado em 1962)

Calligaris, C. (2011). A adolescência. São Paulo: Publifolha.

Carneiro, C., Souza, L. T. R., Coutinho, L. G., \& Silva, R. P. F. (2016). Adolescência e expressões do mal-estar: estudo de casos. Estilos da Clínica, 21(3), 548.572. http://dx.doi.org/10.11606/issn.1981-1624.v21i3p548-572

Cohen, R. H. P., Lessa, C. F., Melo, D. C., Cohen, G., Sias, M. D. D., Serafim, O. G. G., Alves, R. T. M., \& Abecassis, R. (2001). O lugar do psicanalista na escola. Estilos da Clínica, 6(11), 17-26. doi: https://doi.org/10.11606/issn.1981-1624.v6i11p17-26

Coutinho, L. G. (2016). O adolescente e a educação no contemporâneo: o que a psicanálise tem a dizer. Cadernos de Psicanálise, 37(33), 155-174. Recuperado de http://pepsic.bvsalud.org/pdf/cadpsi/v37n33/v37n33a08.pdf 
Cremasco, M. V. F., \& Brunhari, M. V. (2009). Da angústia ao suicídio. Revista Mal-Estar e Subjetividade, 9(3), $\quad 785-814 . \quad$ Recuperado de http://pepsic.bvsalud.org/pdf/malestar/v9n3/03.pdf

Dockhorn, C. N. B. F., \& Macedo, M. M. K. (2015), Estratégia clínico-interpretativa: Um recurso à pesquisa psicanalítica. Psicologia: Teoria e Pesquisa, 31(4), 529-535. http://doi.org/10.1590/0102-37722015042473529535

Dussel, I., \& Caruso, M. (2003). De pedantes, pedagogos e sala de aula. In I. Dussel \& M. Caruso. A invenção da sala de aula (3a. ed., pp. 13-28). São Paulo, SP: Moderna.

Freud, S. (2006). Três ensaios sobre a teoria da sexualidade. In S. Freud. Edição standart brasileira das obras psicológicas completas de Sigmund Freud (J. Salomão, trad., Vol. 7, pp. 119-217). Rio de Janeiro, RJ: Imago. (Trabalho original publicado em 1905)

Freud, S. (2006). Contribuições para uma discussão acerca do suicídio. In S. Freud. Edição standart brasileira das obras psicológicas completas de Sigmund Freud (J. Salomão, trad., Vol. 11, pp. 243-244). Rio de Janeiro, RJ: Imago. (Trabalho original publicado em 1910)

Freud, S. (2006). Sobre o narcisismo: uma introdução. In S. Freud. Edição standart brasileira das obras psicológicas completas de Sigmund Freud (J. Salomão, trad., Vol. 14, pp. 77108). Rio de Janeiro, RJ: Imago. (Trabalho original publicado em 1914)

Freud, S. (2006). O mal-estar na civilização. In S. Freud. Edição standart brasileira das obras psicológicas completas de Sigmund Freud, (J. Salomão, trad., Vol. 21, pp. 63-148). Rio de Janeiro, RJ: Imago. (Trabalho original publicado em 1930)

Gurski, R. (2014). Três tópicos para pensar "a contrapelo" o mal-estar na educação atual. In R. Voltolini (org.) (pp. 166-180). Retratos do mal-estar contemporâneo na educação. São Paulo, SP: Escuta.

Knobel, M. (1986). A síndrome da adolescência normal. In A. Aberastury, \& M. Knobel (orgs.). Adolescência normal: um enfoque psicanalítico (S. M. G. Ballve, trad., 5a ed., pp. 24-62). Porto Alegre, RS: Artmed. (Trabalho original publicado em 1981)

Kupfer, M. C. M. (2007). Educação para o futuro. Psicanálise e educação. São Paulo, SP: Escuta.

Macêdo, K. B. (2012). O desamparo do indivíduo na modernidade. Ecos, 2(1), 95-107. Recuperado de http://www.periodicoshumanas.uff.br/ecos/article/view/742/660

Macedo, M. K. M., Azevedo, B. H., \& Castan, J. U. (2012). Adolescência e psicanálise. In M. K. M. Macedo (org.). Adolescência e psicanálise: intersecções possíveis (pp. 15-54). Porto Alegre, RS: EDIPUCRS.

Macedo, M. K. M., Fensterseifer, L., \& Werlang, B. S. G. (2012). Ressignificações no processo adolescente. In M. K. M. Macedo (org.). Adolescência e psicanálise: intersecções possíveis (pp. 55-71). Porto Alegre, RS: EDIPUCRS.

Macedo, M. M. K., \& Werlang, B. S. G. (2007a). Tentativa de suicídio: o traumático via atodor. Psicologia: teoria e pesquisa, 23(2), 185-194. http://dx.doi.org/10.1590/S0102$\underline{37722007000200009}$

Macedo, M. M. K., \& Werlang, B. S. G. (2007b). Trauma, dor e ato: o olhar da psicanálise sobre uma tentativa de suicídio. Ágora, 10(1), 89-106. http://dx.doi.org/10.1590/S1516$\underline{14982007000100006}$ 
Macedo, M. M. K., Werlang, B. S. G., \& Dockhorn, C. N. B. F. (2008). Vorstellung: a questão da representabilidade. Psicologia: Ciência e Profissão, 28(1), 68-81. http://dx.doi.org/10.1590/S1414-98932008000100006

Mannoni, M. (2005). La teoría en entredicho. In M. Mannoni. La educación impossible (P. Soto, trad., 11a ed., pp. 19-65). Buenos Aires: Siglo Veintiuno Editores. (Trabalho original publicado em 1979)

Martins, V. A. G. (2001). Espaço escolar como herdeiro das funções parentais. Estilos da Clínica, 6(11), 27-32. Doi: https://doi.org/10.11606/issn.1981-1624.v6i11p27-32

Paz, L. R. (1983). Adolescência: Crise de dessimbiotização. In A. Aberastury (org.). Adolescência (R. Cabral, trad., 2a ed., pp. 165-184). Porto Alegre, RS: Artes Médicas. (Trabalho original publicado em 1978)

Pereira, M. R. (2013). Os profissionais do impossível. Educação \& Realidade, 38(2), 485-499. https://doi.org/10.1590/S2175-62362013000200008

Tavares, L. A. T. (2010). Contemporaneidade e "mal-estar". In L. A. T. Tavares. A depressão como "mal-estar" contemporâneo: medicalização e (ex)-sistência do sujeito depressivo (pp. 27-66). São Paulo, SP: Cultura Acadêmica.

\section{Anexo}

Entrevista semiestruturada sobre o impacto da escola na ideação suicida de adolescentes

Nome:

Responsável:

Idade: Escola:

Entrevistador: Data:

1. Como você se descreveria? (Sua personalidade, seu jeito de ser, seu modo de pensar e se comportar.)

2. O que em geral deixa você feliz?

3. O que em geral deixa você mal, triste ou ansioso(a)?

4. Como é a sua família? (Com quem mora, quem cuida de você, como é a relação com seus familiares, o que costumam fazer juntos.)

5. Como você descreveria a escola? E sua vida na escola?

6. Como são as aulas? Você acha que consegue aprender as matérias?

7. Como é sua relação com os professores?

8. Como é sua relação com os colegas?

9. O que você mais gosta na escola? E o que menos gosta?

10. Como se sente a respeito de ir para a escola? Por quê?

11. Se você pudesse mudar algo na sua escola, o que seria?

12. Como você lida com os problemas que surgem na escola?

13. Quando está se sentindo mal, triste ou ansioso(a), você acha que ir para escola melhora ou piora esse sentimento? Por quê?

14. Como é para você ir para a escola quando está se sentindo assim? 
15. Nesses momentos em que você se sente mal, você já pensou em se machucar ou se matar? Como você lidou com esses pensamentos?

16. Você contou para alguém a respeito desses pensamentos? Se sim, o que eles fizeram depois que você lhes contou?

17. Você acha que o que acontece na escola tem relação com esses pensamentos? De que forma? 18. Alguma vez você já tentou se matar?

19. Nesses momentos em que se sente mal, triste ou ansioso(a), você encontra apoio na escola (de amigos, professores, serviço pedagógico, etc.)?

20. Você acha que outros colegas da escola também se sentem assim?

21. Você acha que a sua escola faz alguma coisa para ajudar os alunos que se sentem dessa forma?

22. O que você acha que a escola poderia fazer para ajudar os alunos que se sentem assim?

23. O que você acha que os colegas poderiam fazer para ajudar os alunos que se sentem dessa forma?

24. O que você acha que você poderia fazer para não se sentir mais assim?

25. Tem alguma coisa que eu não tenha perguntado a respeito de você ou sua escola e que você gostaria de falar?

Observações:

Revisão gramatical: Jeferson Luís Machado

E-mail: jefersonjlm@yahoo.com.br

Recebido em junho de 2020 - Aceito em setembro de 2020. 